DOI: https://doi.org/10.14232/actahisp.2021.0.11-20

\title{
UN QUART DE SEGLE D'ESTUDIS CATALANS A LA UNIVERSITAT DE SZEGED
}

\section{TIBOR BERTA}

Universitat de Szeged

\begin{abstract}
Resum: L'objectiu d'aquest treball és presentar la història i els resultats dels estudis catalans a la Universitat de Szeged per commemorar els vint-i-cinc anys de la seva existència. Es detallen les circumstàncies de la seva creació dins el Departament d'Estudis Hispànics de la mateixa universitat. Es presenta l'evolució de les seves activitats docents, científiques i culturals, que mostren els esforços d'aquest centre universitari per difondre l'interès pels estudis catalans a Hongria.
\end{abstract}

Paraules clau: estudis catalans, catalanística hongaresa, catalanística a Szeged.

Abstract: The aim of this work is to present the history and results of the Catalan studies at the University of Szeged in order to commemorate the twenty-fifth anniversary of its existence. The circumstances of its creation within the Department of Hispanic Studies of the same university are detailed. We present the evolution of its teaching, scientific and cultural activities, which show the efforts of this university center to deepen the interest in Catalan studies in Hungary.

Keywords: Catalan Studies, Catalan Studies in Hungary, Catalan Studies in Szeged.

Aquest escrit està dedicat a presentar la història dels estudis catalans que, integrats al Departament d'Estudis Hispànics, van ser introduïts a la Facultat de Lletres de la Universitat Attila József -antecendent de l'actual Facultat d'Humanitats i Estudis Socials de la Universitat de Szeged- el setembre de 1996. En les pàgines següents oferirem, doncs, un repàs breu de l'ensenyament de la llengua catalana, de la producció científica especialitzada en els estudis catalans i l'activitat cultural realitzades a càrrec de la encara jove catalanística de Szeged, commemorant així la seva existència. Intentarem donar compte dels seus resultats, que, segons creiem, són considerables.

Per poder comprendre el pes dels resultats dels estudis catalans de Szeged, convé conèixer els seus antecedents dins Hongria i el context històric en què van nèixer. Com se sap d'un informe detallat de Faluba (2013) sobre la història i periodització de la catalanística hongaresa, després d'un període qualificable de "prehistòric", caracteritzat per l'activitat docent, traductora, editorial i cientifica dels grans precursors Albin Körösi i Ferenc Olivér Brachfeld, la Universitat Eötvös Loránd de Budapest va ser el primer centre universitari hongarès en introduir l'ensenyament sistemàtic del català a l'any acadèmic 1971/72 a càrrec del professor Kálmán Faluba. Durant el període que ha passat d'ençà d'aquesta data clau, l'ensenyament del català a Budapest s'ha desenvolupat des dels cursos optatius de llengua, reforçats per l'establiment d'un lectorat de català (1990), a través del moment culminant de la creació d'una especialització de Filologia 
Un quart de segle d'estudis catalans a la Universitat de Szeged

Catalana (1995) fins la seva integració - com a conseqüència de la reestructuració del sistema educatiu gràcies a la introducció del sistema de Bolonya- en una nova especialització de Filologia Iberoromànica (2007) junt amb el gallec (Faluba, 2013: 910). Aquest primer centre universitari, fundat per Kálmán Faluba, que durant els cinquanta anys transcorreguts des de la seva creació fins l'actualitat ha format generacions d'especialistes en estudis catalans i traductors reconeguts de la literatura catalana a l'hongarès, actualment s'ha convertit en un punt de referència de renom internacional per als estudis catalans a la regió centreeuropea.

Des de la tardor de l'any 1996, segons explica el mateix Faluba (2013: 10), podem comptar amb una segona base de la catalanística hongaresa, l'existent a la Universitat de Szeged; el Departament d'Estudis Hispànics, encarregat de la llicenciatura de Filologia Espanyola en aquesta universitat, només tres anys després de la seva fundació esdevinguda l'any 1993 va introduir cursos de llengua catalana a la seva oferta, fet que concordava amb la intenció originària de no limitar-se a l'ensenyament d'una única llengua. La base d'aquest pas fou assegurada per l'orientació científica del fundador del departament, el catedràtic historiador hispanista Ádám Anderle, interessat per les relacions hispanohongareses i pels temes de la Corona d'Aragó (vid. infra), reforçat per la presència d'un docent lingüista format a la Universitat Eötvös Loránd, que havia aconseguit competència lingüística en català precisament al centre de catalanística a Budapest (Tibor Berta). És necessari destacar que la convocatòria dels primers cursos de català a Szeged va ser possible gràcies al suport financer de la Generalitat de Catalunya i a la col·laboració docent del lectorat de català de Budapest i que aquestes cooperacions, que posteriorment també es van mantenir, com veurem més endavant, van contribuir a la consolidació i bon funcionament dels estudis de català a Szeged. A continuació presentarem aquest procés des de les perspectives de la docència, de la recerca científica, de les activitats culturals i de les cooperacions.

Pel que fa a l'evolució de l'ensenyament de català a aquest centre convé assenyalar dues diferències respecte a la de Budapest. La primera és que a la Universitat de Szeged l'ensenyament des de l'inici es realitza en el marc d'un pla d'estudis propi-encara que també s'ofereixen cursos de català optatius-, i en finalitzar els seus estudis, l'alumne rep un document que certifica que ha complert amb els requisits del programa de català. L'altra consisteix en que la configuració del programa docent està -i ha estat semprededicat únicament als estudis catalans. Cal dir, a més, que els vint-i-cinc anys de la història de l'ensenyament institucionalitzat del català a la Universitat de Szeged es pot dividir en dos períodes: els primers 10 anys entre 1996 i 2005, i el període posterior al 2005, que significa l'ensenyament segons el sistema de Bolonya, iniciat a Hongria el 2006. Des del punt de vista del contingut és comú el fet que el programa comenci amb cursos de llengua per a principiants, perquè l'alumnat generalment no té coneixements de llengua catalana, i només des del segon semestre apareixen gradualment assignatures de cultura, d'història, de literatura i de lingüística. 
En el primer període, entre 1996 i 2005, la docència es realitzava en un programa d'especialització ofert a tots els alumnes de la Facultat de Lletres, amb el títol d'Especialització en llengua, literatura $i$ civilització catalanes. El programa era de quatre semestres -és a dir, dos anys- de duració, amb sis hores setmanals de classe. Dos terços de les assignatures eren de llengua catalana, i la resta es dedicava a temes de cultura, a la història de la Corona d'Aragó, a la Catalunya d'avui, a la literatura medieval i contemporània, i a la història de la llengua catalana. En la docència hi participaven els professors Ádám Anderle (història) i Tibor Berta (història de la llengua), però la gran part dels cursos anaven a càrrec del professor nadiu o lector compartit amb la Universitat Eötvös Loránd de Budapest (Carme Rodés, Eloi Castelló, Adrià Castells i Jordi Giné). El fet que el lectorat fos compartit i la presència del lector a Szeged es limités només a un dia determinat de la setmana no feia possible impartir classes paral·lelament en dos cursos, així només cada dos anys es posava en marxa el programa amb alumnes nous. En aquest període el nombre d'alumnes variava entre vuit i dotze. Des de l'ensenyament de la llengua catalana va sorgir immediatament la demanda d'organitzar proves de certificat internacional de català, primer el nivell bàsic, després el nivell elemental. Al començament, en els exàmens orals, hi col·laboraven el professor Kálmán Faluba i la professora Ildikó Szijj com a examinadors.

El segon període va començar, doncs, el 2006, caracteritzat per la introducció del sistema de Bolonya. En aquest nou sistema el programa de català es va integrar com un programa d'especialització, un tipus de minor, també de quatre semestres de duració, però de 50 crèdits. Això va significar l'ampliació de les hores de classe i també va fer possible la incorporació de la gramàtica descriptiva al pla d'estudis com a assignatura nova. Aquesta transformació exigia, però, que el programa es convoqués cada any, no només cada dos anys, i això només era possible tenint un lectorat propi, i amb la presència i col·laboració permanent d'un lector a Szeged. Per això, encara el 2005, es va sol-licitar a l'Institut Ramon Llull que es creés un lectorat independent, amb plaça de lector a temps complet al Departament d'Estudis Hispànics. L'Institut Ramon Llull, tenint en compte els resultats previs, va acceptar la proposta, i es va encarregar del finançament complet de la nova plaça. El 2006 la Facultat de Lletres de la Universitat de Szeged ja podia completar la subvenció amb un sou i subvenció d'allotjament, oferint un contracte legal al lector. Aquesta consolidació del lectorat independent a Szeged va fer possible que el Departament comptés amb la presència d'un lector propi -Andrea Abad (2007-2008), Jordi Gimeno (2008-2013), Laia Serret Prunera (20132016), Andreea-Isabella Ştefan (2016-2020) i Enric Fernández Serra (2020-)- i que el programa de català acceptés alumnes nous cada any. Des de 2009 el minor de català s'ofereix com a especialització a qualsevol alumne de la universitat. Més recentment s'ha ampliat l'oferta de nivells en els cursos optatius de llengua, el que ha fet possible que s'organitzessin proves de català de nivells superiors (B2 i C1), ja amb la participació de Tibor Berta com a examinador. 
Un quart de segle d'estudis catalans a la Universitat de Szeged

Els estudis de català, que s'anaven consolidant a Szeged a poc a poc, superaven els límits d'un programa docent de 50 crèdits, dedicat a l'ensenyament del català. De vegades, i de forma més o menys regular, entre els treballs finals de llicenciatura i de grau de l'alumnat de la carrera de Filologia Espanyola n'hi havia alguns que tractaven temes de literatura, política, política lingüística i sociolingüística del domini lingüístic del català. Panyi (2000) i Molnár (2016), actuant en l’àrea preferida del professor Anderle, van presentar l'espai polític de Catalunya de la dècada dels 90 i el catalanisme contemporani, respectivament; examinant la correlació entre societat i literatura, Gyeraj (2000) va examinar l'evolució de la identitat catalana en la revista Avenç i Vass (2000) els possibles models històrics del protagonista de la novel·la Tirant lo Blanch. Fins ara, l'àrea de la lingüística ha estat la més productiva amb sis treballs, tres dels quals -Zala (1995), Gajár (2007) i (Vincze, 2016) - versen sobre temes de política lingüística o sociolingüística, mentre que en altres dos el català es compara o contrasta amb el castellà -Nagy (2002) i Gál (2018) - i en el més recent s'analitza l'influx fonètic del català en el castellà de Barcelona -Ambrus (2019)-. A més d'aquests treballs realitzats dins els marcs dels programes educatius que funcionaven a càrrec del mateix Departament d'Estudis Hispànics, cal esmentar-ne altres, vinculats en un sentit més ample amb aquest, per haver estat duts a terme a altres unitats universitàries i a nivells superiors de l'ensenyament, per autors que van ser, al menys parcialment, formats al centre de Szeged. A nivell de màster, el treball de Posztós (2014) -llegit i defès a la Universitat Rovira i Virgili- és una aportació important a la història de la presència d'Hongria i dels hongaresos en la literatura catalana; a nivell de doctorat, el de Nagy (2013) - defès al programa de doctorat en lingüística teòrica de la Universitat de Szeged- destaca per ser la primera tesi doctoral de lingüística a Hongria que és dedicada enterament a un tema de la gramàtica històrica de la llengua catalana, mentre que el de Nemes (2018) -defès al programa de doctorat en història del món hispànic de la Universitat de Szeged- examina un segment de la memòria històrica catalana com a àrea de contacte entre història i literatura.

Pel que fa a la activitat científica del Departament d'Estudis Hispànics sobre temes catalans, cal tornar a ressaltar que aquesta és un tret característic del centre hispanista szegedí des del moment de la seva fundació. Els primers estudis centrats en temes catalans, que constituien els antecedents de la introducció de l'ensenyament del català, van aparèixer-hi en els anys 90 dins el marc dels estudis hispànics orientats fortament cap a temes d'història. En les recerques del professor Ádám Anderle, fundador del Departament, catedràtic d'història, dedicat, entre altres coses, a la història de les relacions hispanohongareses, hi estaven presents els temes vinculats amb la història de la Corona d'Aragó i, molt especialment, amb les relacions que aquesta monarquia va tenir amb el Regne d'Hongria durant l'Edat Mitjana. Encara el 1993, el mateix any de la fundació del Departament, va publicar en hongarès la monografia de l'Olivér Brachfeld sobre Violant d'Hongria, reina d'Aragó (Brachfeld, 1993), que va tenir una segona edició l'any següent. També va començar, però, a publicar estudis que comunicaven els 
resultats de les seves pròpies recerques. En un primer estudi, publicat en hongarès (Anderle, 1994) presenta la figura de Constança d'Aragó, reina d'Hongria entre 1198 i 1204 , i en un article següent publicat en anglès (1995) i reproduït en hongarès (1996) analitza les negociacions que tenien com a objectiu l'oferiment de la corona hongaresa a Alfons el Magnànim de part de l'aristocràcia hongaresa. Alguns anys més tard, a càrrec del mateix Anderle, va ser editat un volum dedicat als "mil anys de relacions catalanohongareses" (2001), que recull les versions escrites de conferències que diversos col·laboradors hongaresos interessats per temes catalans -d'història, política, literatura, cultura i lingüística- havien dictat en un col·loqui nacional organitzat pel Departament d'Estudis Hispànics. Més recentment Lénárt (2017a) ofereix un panorama històricopolític de Catalunya en el segle XX i un breu resum de la filmografia actual catalana (2017b) en articles escrits en hongarès.

En l'àrea de la lingüística el primer estudi dedicat enterament al català -més concretament a la seva caracterització tipològica- és el de Berta (2001), publicat en hongarès en el volum -ja esmentat- dedicat a les relacions catalanohongareses; en Berta (2018a), treball més aviat informatiu que no pas científic, també publicat en hongarès, s'ofereix un análisi de la correlació entre la identitat catalana i la llengua catalana. A més d'aquests articles dedicats als lectors hongaresos no especialistes interessats en els estudis de català, cal esmentar-ne d'altres, més estrictament enfocats en temes de lingüística catalana: Berta $(2011 ; 2013 ; 2015 ; 2018 b)$ analitza corpus formats per textos antics escrits en català, examinant diferents aspects de la formació dels temps compostos en la història del català, amb atenció especial als aspectes estilístics, sociolingüístics i dialectals de la pèrdua de la concordança entre el participi i l'objecte directe.

A més de publicacions d'autors que pertanyen institucionalment al personal docent $\mathrm{i}$ investigador del Departament d'Estudis Hispànics, també mereixen ésser esmentades altres que estan vinculades amb ell. Nagy C., membre del MTA-DE-SZTE Grup de Recerca en Lingüística Teòrica de la Xarxa de Recerca Eötvös Loránd (ELKH), qui va obtenir formació en filologia hispànica i en estudis catalans al Departament d'Estudis Hispànics de Szeged, dedica gran part de la seva activitat científica a temes de gramàtica històrica catalana dins els marcs de la pragmàtica històrica: en diversos estudis (Nagy C., 2008a; 2008b) i molt especialment en la seva monografia (Nagy C., 2019) analitza els inicis del procés de gramaticalització de la construcció anartinfinitiu des d'aquesta perspectiva oferint aportacions teòriques importants també per a la metodologia de la recerca lingüística; més recentment (Nagy C., 2018a; 2018b; 2020) examina les directives de cortesia amb atenció particular a les construccions formades amb el verb plaure en el català medieval. També recentment, Sermann (2014; 2021), docent del Departament d'Italianística szegedí, especialitzada en traductologia i terminologia, formada en filologia hispànica al mateix centre universitari, presenta en diferents estudis publicats en hongarès $(2014 ; 2020 ; 2021)$ les bases de dades catalanes Cercaterm i Neoloteca, no només com a recursos útils per als professionals de traducció, sinó -com 
Un quart de segle d'estudis catalans a la Universitat de Szeged

ressalta Sermann (2020) - també mitjans que serveixen per expressar la identitat catalana. Nemes, traductora de literatura, doctora pel programa de doctorat en història vinculat amb el Departament d'Estudis Hispànics, examina la correlació entre llengua, literatura, història $\mathrm{i}$ identitat des de la perspectiva catalana en diversos estudis (2015; 2016; 2020). Alguns dels articles esmententats -Nagy C. (2008a); Nemes (2016; 2020)van ser publicats en Acta Hispanica, revista científica del departament, oberta també cap a temes d'estudis catalans, o en altres publicacions editades pel Departament d'Estudis Hispànics.

L'activitat de l'alumnat no es limita a presentar-se en les proves del certificat internacional de català i a elaborar temes de catalanística en els treballs obligatoris, sinó que també mostra interès per participar en concursos literaris o de traducció, els millors productes dels quals es publiquen en la revista Homo Hispanisticus, destinada a suportar les ambicions literaràries i científiques de les noves generacions. El 2009, amb el suport de l'Institut Ramon Llull, va tenir lloc a la Universitat de Szeged la primera jornada universitària catalanohongaresa, un esdeveniment cultural i científic, que des del 2011 s'organitza de forma alternant entre la Universitat Eötvös Loránd de Budapest i la Universitat de Szeged i es proposa difondre els resultats científics de la catalanística i diversos aspectes culturals vinculats amb el domini lingüístic del català, que, però, degut a la pandèmia COVID-19, no va ser organitzada el curs passat. També va sorgir al lectorat de català de Szeged la idea d'organitzar un seminari de traducció literària ibèrica amb la participació de l'alumnat que, fins la pandèmia COVID-19, s'organitzava cada any a la Casa del traductor, a la localitat hongaresa de Balatonfüred. Aquestes activitats, conferències, presentacions de llibres han resultat formes adequades d'atreure l'atenció del públic - no només universitari- i d'establir el contacte amb el món de fora de la universitat.

Les activitats científiques i culturals esmentades, dutes a terme amb la participació comuna dels membres de la comunitat formada pels especialistes interessats per temes catalans, també mereixen atenció perquè mostren la forma de funcionar de la catalanística de Szeged. Aquesta, molt productiva especialment si tenim en compte que el seu personal docent és reduït i que es troba dins un departament també relativament petit, no es pot comprendre sense tenir en consideració la cooperació professional amb altres centres de catalanística dins i fora d'Hongria. Anteriorment ja hem fet referència al suport que el programa de catalanística de la Universitat Eötvös Loránd de Budapest va oferir al de Szeged als inicis de la seva existència i hem vist que la col·laboració entre aquests dos centres hongaresos d'estudis catalans ha continuat. Com hem vist, l'orientació professional del Departament d'Estudis Hispànics de la Universitat de Szeged inclou els estudis catalans, i això s'observa també en el fet que les seves relacions científiques i docents integren contactes amb centres d'estudis catalans de diverses universitats europees; a més d'universitats del domini lingüístic català Universitat d'Alacant, Universitat de Barcelona i Universitat Rovira i Virgili-, també formen part dels contactes basats en convenis ERASMUS la Universitat Adam 
Mickiewicz de Poznań (Polònia) i la Universitat Masaryk de Brno (República Txeca). Gràcies a aquesta xarxa de contactes professionals van fer una estància docent al Departament d'Estudis Hispànics membres del professorat de centres diferents de filologia catalana com ara Maria Isabel Guardiola Savall (Universitat d'Alacant), Sandra Montserrat Buendia (Universitat d'Alacant) i Xavier Rull (Universitat Rovira i Virgili). Gràcies al suport de l'Institut Ramon Llull, les jornades universitàries catalanohogareses organitzades pel Departament d'Estudis Hispànics van comptar amb les aportacions científiques d'especialistes destacats d'alguna àrea dels estudis catalans, com ara Agustí Alcoberro i Pericay (Universitat de Barcelona), Gabriel Ensenyat Pujol (Universitat de les Illes Balears) i Francesc Xavier Lamuela García (Universitat de Girona). També cal esmentar que les activitats científicoculturals de les jornades universitàries catalanohongareses organitzades a Szeged regularment compten amb el suport de la Col·leció d'Hispanística de la Biblioteca Universitària Klebelsberg, enriquida amb publicacions especialitzades en estudis catalans i amb obres de la literatura catalana gràcies a generoses donacions de diferents entitats editorials i culturals d'Hongria i de Catalunya.

Aquest resum demostra que durant la seva existència fins ara de vint-i-cinc anys la catalanística a la Universitat de Szeged, situada estructuralment dins el Departament d'Estudis Hispànics, dins el marc de les seves modestes possibilitats i gràcies al suport dels seus col-laboradors, ha tingut aportacions considerables tant a diversos nivells de la docència universitària, com a diferents àrees de la recerca científica a difondre l'interès pels estudis catalans i per la cultura del domini lingüístic del català.

\section{Referències bibliogràfiques}

\section{Treballs finals de llicenciatura o de grau de temes catalans al Departament d'Estudis Hispànics}

Ambrus, Lili (2019). Rasgos fonéticos del español de Cataluña a través de análisis de una serie televisiva. Szeged: Universidad de Szeged.

Gajdár, Zsuzsanna (2007). Politicas lingüisticas de las Comunidades Autónomas catalanohablantes de España. Szeged: Universidad de Szeged.

Gál, Diána (2018). Análisis contrastivo del sistema fonológico del castellano y del catalán. Szeged: Universidad de Szeged.

Gyeraj, Mónika (2000). Buscando la identidad: L'Avenç. Szeged: Universidad de Szeged. Molnár, Balázs (2016). El catalanismo contemporáneo. Szeged: Universidad de Szeged.

Nagy, Katalin (2002). Los pretéritos de indicativo en español y catalán en los siglos XIII-XIV. Szeged: Universidad de Szeged. 
Un quart de segle d'estudis catalans a la Universitat de Szeged

Panyi, Krisztina (2000). Panorama del espacio politico catalán en los años 90 (1992-2000). Szeged: Universidad de Szeged.

Vincze, Diána (2016). La política lingüistica y uso del catalán y castellano en Cataluña y la Comunidad Valenciana. Szeged: Universidad de Szeged.

Vass, Eszter (2000). Tirant lo Blanch. Los modelos históricos para la figura de Tirant. Szeged: Universidad de Szeged.

Zala, Anikó (1995). La situación sociolingüistica actual del catalán: resultado de un proceso bistórico. Szeged: Universidad de Szeged.

\section{Obres citades}

Anderle, Ádám (red.) (2001). Kutatási közlemények III. A magyar-katalán kapcsolatok ezeréve. Szeged: Hispánia.

Anderle, Ádám (1996). Az aragón kapcsolat. Történelmi Sz̨mle, 38(4). 401-411.

Anderle, Ádám (1995). Alfonso V, el Magnánimo and the Hungarian Throne. Mediterrán Tanulmányok, 6. 17-28.

Anderle, Ádám (1994). Aragóniai Konstancia a spanyol történetírásban. Világtörténet, 1994(1). 32-38.

Berta, Tibor (2018a). Nyelv és identitás: a katalán esete. Szépirodalmi Figyeló, 2018/1. 45-54.

Berta, Tibor (2018b). La falta de concordança del participi dels temps compostos en textos valencians del segle XV. Dins: Massot i Muntaner, Josep (ed.). Homenatge a Kálmán Faluba 2. Estudis de llengua i literatura catalanes. Barcelona: Publicacions de l'Abadia de Montserrat. 119-145.

Berta, Tibor (2015). On the Lack of Agreement of the Participle of Compound Tenses in Old Non Literary Catalan Texts. Studia Romanica Posnaniensia, 42(5). 23-41.

Berta, Tibor (2013). Sobre la manca de concordança del participi dels temps compostos en textos catalans antics. Dins: Bartual, Carles - Déri, Balázs - Faluba, Kálmán - Szijj, Ildikó (eds.). Catalanística a Hongria (1971/72-2011/2012). Actes del Simposi Internacional de Catalanística. Budapest, 24-26 d'abril de 2012. Budapest: Universitat Eötvös Loránd de Budapest, Facultat de Lletres, Estudis d'Iberoromanística. 49-56.

Berta, Tibor (2011). A participium egyeztetésének elmaradása a középkori katalán összetett igeidőkben. Dins: Déri, Balázs - Menczel, Gabriella - Szijj, Ildikó (eds.). Per multos annos. Faluba Kálmán tanár úr 70. születésnapjára. Budapest: L'Harmattan. 51-62.

Berta Tibor (2001). A katalán az iberoromán nyelvek között. Dins: Anderle Ádám (red.): Kutatási közlemények III. A magyar-katalán kapcsolatok ezer éve. Szeged: Hispánia. 87-97.

Brachfeld, F. Olivér (1993). Arpád-házi Jolánta, Aragónia királynéja. Szeged: Hispanisztika Tanszék.

18 | Acta Hispanica, Hungría, Supplementum III: 11-20, 2021, ISSN 1416-7263, e-ISSN 2676-9719 
Tibor Berta

Faluba, Kálmán (2013). Història i periodització de la catalanística hongaresa. Dins: Bartual, Carles - Déri, Balázs - Faluba, Kálmán - Szijj, Ildikó (eds.). Catalanística a Hongria (1971/72-2011/12). Budapest: Universitat Eötvös Loránd, Facultat de Lletres, Estudis d'Iberoromanística. 7-11.

Lénárt, András (2017a). Katalónia a 20. században. Rubicon, 28(11). 54-63.

Lénárt, András (2017b). Autonóm kamerával Hispániában: a mai katalán film. Filmvilág, 60(11). 42-45.

Nagy C., Katalin (2020). Plàcia a Déu 'May it Please God': Constructions with the Verb Plaure 'Please' in Medieval Catalan. Corpus Pragmatics: International Journal of Corpus Linguistics and Pragmatics, 4(3). 293-332.

Nagy C., Katalin (2019). Data and Argumentation in Historical Pragmatics. Grammaticalization of a Catalan Motion Verb Construction. Sheffield: Equinox.

Nagy C., Katalin (2018a). Történeti beszédaktus-kutatás: a középkori katalán plaure 'tetszik' igével alkotott szerkezetekről. Jelentés és Nyelvhasználat, 5. 215-242.

Nagy C., Katalin (2018b). (Udvarias) direktívák a középkori katalánban. Dins: Berta, Tibor - Csikós, Zsuzsanna - Jancsó, Katalin - Katona, Eszter - Lénárt, András Praefort, Veronika (eds.). 25 év - 25 tanulmány. 1993-2018. Fejezetek a Hispanisztika Tanszéé történetéböl. 25 años - 25 ensayos. Capitulos de la historia del Departamento de Estudios Hispánicos. 1993-2018. Szeged: JatePress. 229-242.

Nagy C., Katalin (2013). A katalán „anar + fönévi igenév“ szerkezet grammatikalizációs jelentésváltozásának kezdeti szakaszáról történeti pragmatikai megközelitésben. Tesi doctoral. Manuscrit. Szeged: Universitat de Szeged.

Nagy C., Katalin (2008a). Aspecto verbal en la evolución de la construcción catalana "anar + infinitiu". Acta Hispanica, 13. 75-96.

Nagy C., Katalin (2008b). Data in historical pragmatics: a case study on the Catalan periphrastic perfective past. Dins: Kertész, András - Rákosi, Csilla (eds.). New approaches to linguistic evidence. Pilot studies. (MetaLinguistica, vol. 22.) Frankfurt am Main: Lang. 171-197.

Nemes, Krisztina (2020). La imagen de Marruecos en la "nueva" literatura catalana o el poder de la identidad. Acta Hispanica, 25. 195-205.

Nemes, Krisztina (2018). Történelem és emlékezet a Mequinensa mitosz̧ban: Jesús Moncada A folyók városa címú regényének történelemképe (1870-1970). Tesi doctoral. Manuscrit. Szeged: Universitat de Szeged.

Nemes, Krisztina (2016). La larga transición del libro en catalán. Dins: Berta, Tibor Csikós, Zsuzsanna - Jancsó, Katalin - Katona, Eszter - Lénárt, András - Praefort, Veronika (eds.). Transiciones: De la dictadura a la democracia. Szeged: Departamento de Estudios Hispánicos/Centro de Estudios Interamericanos. 324-335.

Nemes, Krisztina (2015). Függetlenség - Állam - Nyelv: Katalónia különös esete. Létünk, 2015(2). 117-128. 
Un quart de segle d'estudis catalans a la Universitat de Szeged

Posztós, Ildikó Piroska (2014). Hongria i hongaresos en la literatura catalana: El cas de Violant d'Hongria. Treball de fi de màster. Manuscrit. Tarragona: Universitat Rovira i Virgili.

Sermann, Eszter (2021). A dokumentációhoz kapcsolódó fogalmak a Cercaterm katalán terminológiai adatbázisban. Dins: Fóris, Ágota - Bölcskei, Andrea (eds.). Tartalomfejles zৃtés és dokumentáció: Nyelvészeti Kutatások. Budapest: Károli Gáspár Református Egyetem / L'Harmattan Kiadó. 247-262.

Sermann, Eszter (2020). A Neoloteca katalán terminológiai adatbázis mint a nyelvi identitás kifejezésének eszköze. Dins: Bakti, Mária - Újvári, Edit (eds.). Nyelv és identitás. Szeged: Juhász Gyula Felsőoktatási Kiadó. 49-60.

Sermann, Eszter (2014). A TERMCAT Terminológiai Központ és a Cercaterm terminológiai adatbázis. Modern Nyelvoktatás, 20(4). 97-100. 